\section{ECCOMAS}

Proceedia

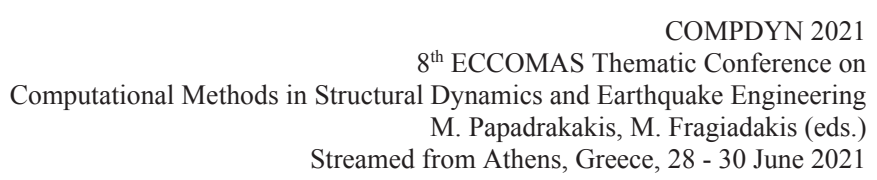

Streamed from Athens, Greece, 28 - 30 June 2021

\title{
MECHANICAL PROPERTIES CHARACTERISATION OF FRPS UNDER ELEVATED TEMPERATURES
}

\section{Christina Papadimitriou ${ }^{1 *}$, Lambros Kotoulas ${ }^{1}$, Nikolaos Makris ${ }^{1}$, Lazaros Melidis ${ }^{1}$ and Konstantinos Katakalos ${ }^{1}$}

${ }^{1}$ Aristotle University of Thessaloniki

Laboratory of Experimental Strength of Materials and Structures, Thessaloniki, 54124

e-mail: \{chrdimpap,kkatakal\}@civil.auth.gr, \{1pkotoulas,nsvmakris\}@gmail.com

https://strength.civil.auth.gr

\begin{abstract}
Fiber-reinforced polymers (FRP) are rapidly gaining acceptance from the construction sector due to their large effectiveness. They are mainly used as confining reinforcement for concrete columns and as tensile reinforcement for concrete beams and slabs. FRPs are already used to a large extent at applications such as bridges and parking lots, where elevated temperatures are not the main risk. Their increasing use as structural reinforcement is hampered by the concern related with their behavior at elevated temperatures as the relevant research is deficient. Thanks to the significant advantage of FRPs' mechanical properties, further investigation into the influence of heating on their mechanical behavior may solve many doubts. The present study examines the influence of temperatures of 50,100 and $250^{\circ} \mathrm{C}$ on the tensile strength of FRP laminates with carbon fibers (CFRP). In addition, the resistance of CFRP specimens to lowcycle thermal loading at the temperatures of 50, 100 and $250^{\circ} \mathrm{C}$ under constant tensile load was investigated. The experiments carried out in the laboratory of Experimental Strength of Materials and Structures of Aristotle University of Thessaloniki.
\end{abstract}

Keywords: fiber reinforced polymer, thermomechanical characterization, elevated temperatures, civil engineering applications.

ISSN:2623-3347 @ 2021 The Authors. Published by Eccomas Proceedia.

Peer-review under responsibility of the organizing committee of COMPDYN 2021.

doi: $10.7712 / 120121.8686 .19500$ 


\section{INTRODUCTION}

The FRPs are composite materials consisting of continuous high-strength fibers, which are embedded into a polymer matrix (usually organic) [1]. The fibers are the reinforcing elements, whereas the polymer matrix is the connecting material which protects them and transfers the loads to and between the fibers [1]. In the construction sector, the main types of fibers used are glass, carbon (inorganic) and aramid fibers (organic polymers). The use of these materials in civil engineering applications is constantly expanding, due to their important advantages. High resistance to corrosion, high strength-to-weight ratio, high stiffness, appropriate fatigue performance, electric insulation and easy installation are some of them [2],[3]. However, FRPs, according to surveys, show sensitivity to high temperatures. Elevated temperatures cause reduction in elastic modulus and strength [2]. These possibly result in large deflections, loss of reinforcement and eventually collapse [2].

Specifically, the glass transition temperature $\mathrm{Tg}$ is an important parameter to be considered, as above this the mechanical characteristics of the FRPs are reduced dramatically [4]. The polymer is converted from a hard, glassy material to a soft and rubbery one [2]. This leads to loss of adhesion and fibers' removal from the matrix. The resin is no longer able to transfer the loads evenly to the fibers [4]. As a result, some of the fibers are being further loaded, probably exceed their strength and fail [4]. It is also marked that a significant increase in temperature, except in the case of fire, can be caused by direct exposure to sunlight [4]. Especially, dark surfaces are able to reach temperatures of $70^{\circ} \mathrm{C}[4]$.

The effects of elevated temperatures on the mechanical properties of FRPs are of concern and research into this is limited. However, thanks to the significant advantages of FRPs it is worth further investigation. The present experimental work focuses on the thermo-mechanical behavior of the CFRPs laminates under monotonic mechanical loading, low-cycle fatigue and thermal loading. The experiments carried out in the laboratory of Experimental Strength of Materials and Structures of Aristotle University of Thessaloniki and the investigation parameters were the tensile stress and the temperature.

\section{MATERIALS AND METHODS}

The material of the specimens which were used in the current research was FRP laminate with unidirectional carbon fiber layers embedded in organic matrix with $\mathrm{Tg}=58^{\circ} \mathrm{C}$. According to the manufacturer data sheet, layer's thickness was $0.129 \mathrm{~mm}$, and the tensile strength and the elastic modulus of dry fibers were 4,000 MPa and 230,000 MPa, respectively. Twenty CFRP specimens of $250 \mathrm{~mm}$ length, $15 \mathrm{~mm}$ width and $1.8 \mathrm{~mm}$ thickness were prepared for the tests. (see figure 1) Their dimensions were measured using a digital caliper. Nine of them were tested at room temperature $\left(\mathrm{RT}=16^{\circ} \mathrm{C}\right)$ and they were used as controls while the rest of the specimens were exposed to elevated temperatures $\left(50,100,250^{\circ} \mathrm{C}\right)$. 


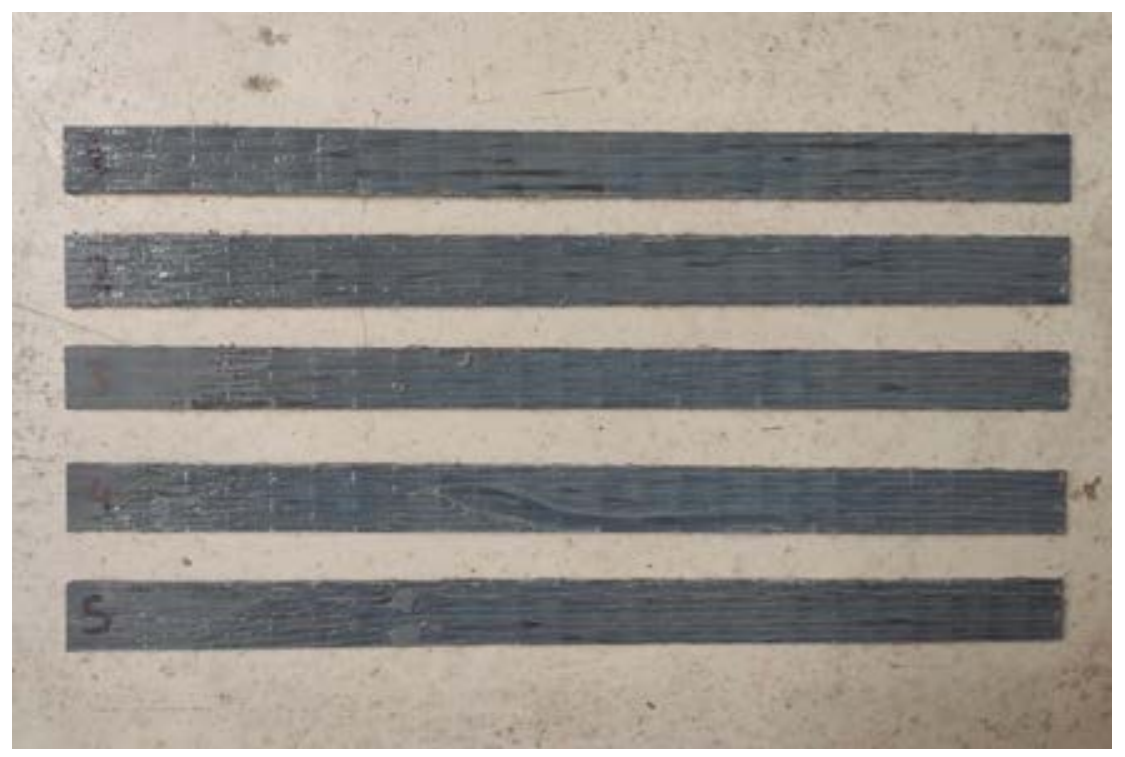

Figure 1: Investigated specimens.

The tensile tests were performed using a universal testing machine Instron of $50 \mathrm{kN}$ maximum capacity. Concurrently, the Bluehill software was used for the data export. (see figure 2) A clip-on extensometer was installed in order to measure the strain values. The tensile testing was conducted using a standard head stroke rate of $2.0 \mathrm{~mm} / \mathrm{min}$ until failure. The Instron machine was equipped with an electric furnace for the heating of the specimens. The maximum operating temperature of the furnace is $260{ }^{\circ} \mathrm{C}$ and the applied heating rate was $10{ }^{\circ} \mathrm{C} / \mathrm{min}$. The cooling up to the room temperature was held in a physical way, so the cooling rate was relatively slow. While the furnace was closed the deflection was measured by the Instron machine head stroke. The experimental setup for both room and elevated temperatures is shown in figure 3 .

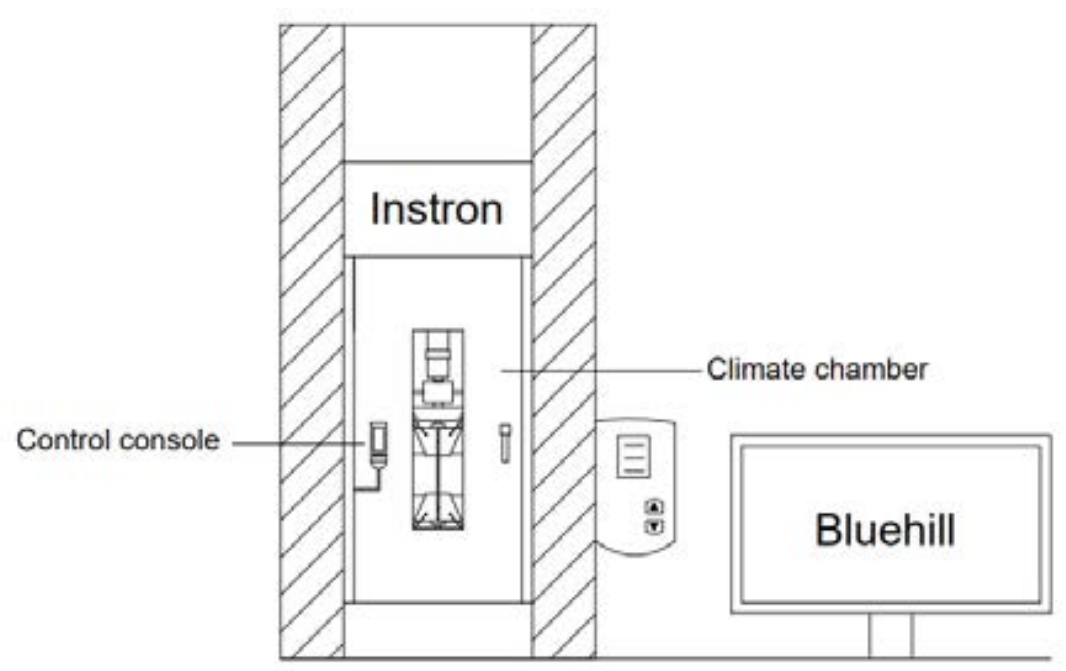

Figure 2: Experimental setup with climate chamber [5]. 

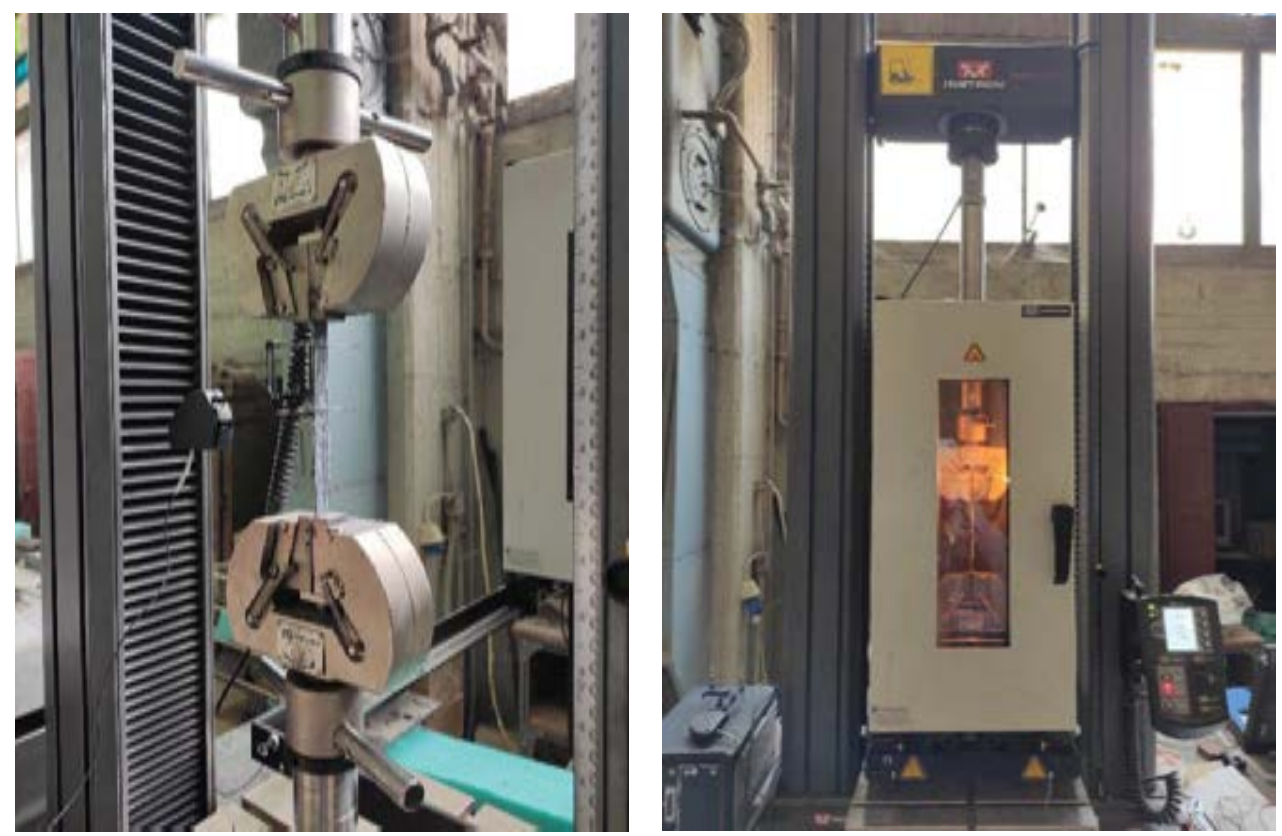

Figure 3: Experimental setup for room temperature and for elevated temperatures.

As mentioned, nine tests were occurred at room temperature $\left(16{ }^{\circ} \mathrm{C}\right)$. The first five specimens (FRPspec1-5) were tested under monotonic, uniaxial tension until failure. From the average value of these specimens' strength, their maximum tensile strength was determined. Subsequently, four specimens were submitted to low-cycle fatigue tests of fifty loading-unloading cycles. The maximum load of the cycle was equal to the $50 \%$ of the average tensile strength for the two specimens (FRPspec6,14) and 75\% for the other two specimens (FRPspec7,15). The rate of the tensile loading was $1000 \mathrm{~N} / \mathrm{min}$ for the cyclic tests. After the fatigue loading the four specimens were tested under monotonic, uniaxial tension up to failure. The information of experiments under room temperature is shown in table 1.

Table 1: Detailed information of experiments under room temperature.

\begin{tabular}{|c|c|c|c|c|c|}
\hline \multirow[t]{2}{*}{ Name } & \multicolumn{2}{|c|}{$\begin{array}{l}\text { Dimensions } \\
\quad(\mathrm{mm})\end{array}$} & \multirow[t]{2}{*}{ Loading } & \multirow{2}{*}{$\begin{array}{c}\mathrm{T} \\
\left({ }^{\circ} \mathrm{C}\right)\end{array}$} & \multirow[t]{2}{*}{ Comments } \\
\hline & $\mathbf{t}$ & b & & & \\
\hline FRPspec1 & 1.63 & 15.74 & MUT $^{* 1}$ & $\mathrm{RT}(=16)$ & MUT up to failure \\
\hline FRPspec2 & 1.74 & 17.26 & MUT & RT & MUT up to failure \\
\hline FRPspec3 & 1.71 & 14.68 & MUT & RT & MUT up to failure \\
\hline FRPspec4 & 1.65 & 16.56 & MUT & RT & MUT up to failure \\
\hline FRPspec5 & 1.78 & 15.95 & MUT & RT & MUT up to failure \\
\hline FRPspec6 & 2.06 & 16.26 & $\begin{array}{l}\text { LCF }^{* 2}, \\
\text { MUT }\end{array}$ & RT & $\begin{array}{l}\text { LCF ( } 50 \text { cycles) with max load } 50 \% \text { of } \\
\text { the tensile strength and MUT up to failure }\end{array}$ \\
\hline FRPspec14 & 1.74 & 15.15 & LCF, MUT & RT & $\begin{array}{l}\text { LCF ( } 50 \text { cycles) with max load } 50 \% \text { of } \\
\text { the tensile strength and MUT up to failure }\end{array}$ \\
\hline FRPspec7 & 1.98 & 16.04 & LCF, MUT & RT & $\begin{array}{l}\text { LCF ( } 50 \text { cycles) with max load } 75 \% \text { of } \\
\text { the tensile strength and MUT up to failure }\end{array}$ \\
\hline FRPspec15 & 1.85 & 16.34 & LCF, MUT & RT & $\begin{array}{l}\text { LCF ( } 50 \text { cycles) with max load } 75 \% \text { of } \\
\text { the tensile strength and MUT up to failure }\end{array}$ \\
\hline
\end{tabular}

*1Monotonic Uniaxial Tension, *2Low Cycle Fatigue $(\mathrm{n}=50)$ 
The rest eleven specimens were exposed under elevated temperatures. The first six of them were submitted to thermal loading at temperatures of $50{ }^{\circ} \mathrm{C}$ (FRPspec 8,11 ), $100{ }^{\circ} \mathrm{C}$ (FRPspec9,12) and $250{ }^{\circ} \mathrm{C}$ (FRPspec10,13). Once the furnace reached the target temperature, each specimen remained at this temperature for $30 \mathrm{~min}$ in order to obtain a uniform temperature distribution. When the specimen FRPspec 8 was heated at $50{ }^{\circ} \mathrm{C}$, the uniaxial tensile test was performed at that temperature level. However, the tensile tests for the FRPspec11, the FRPspec9,12 and the FRPspec 10,13 at $50{ }^{\circ} \mathrm{C}, 100{ }^{\circ} \mathrm{C}$ and $250{ }^{\circ} \mathrm{C}$, respectively, were performed after the specimens left to cool down to room temperature $\left(16^{\circ} \mathrm{C}\right)$. The cooling process was achieved by opening the door of the furnace. After the cooling, the specimens were tested under monotonic, uniaxial tension until failure, as described before.

In fact, CFRPs applied in concrete structures are usually under both imposed load and elevated temperatures from the environmental changes. Therefore, we decided to investigate the last five specimens under cyclic thermal loading while applying at the time uniform axial tensile loading. These specimens were subjected to monotonic, uniaxial tension constantly at $50 \%$ of their average tensile strength. A standard head stroke rate of $2.0 \mathrm{~mm} / \mathrm{min}$ was used until the target load value. Then, the specimens remained under this constant axial load. After three minutes, cyclic thermal loading was imposed to the specimens. We reached the temperatures of $50{ }^{\circ} \mathrm{C}$ (FRPspec16), $100{ }^{\circ} \mathrm{C}$ (FRPspec17,18) and $250{ }^{\circ} \mathrm{C}$ (FRPspec19,20). The low-cycle thermal loading consisted of heating-cooling cycles up to failure. The maximum number of the cycles was three. Each cycle concluded the heating process with a rate of $10^{\circ} \mathrm{C} / \mathrm{min}$, a holding time of $15 \mathrm{~min}$ at the target temperature and the cooling process to the room temperature $\left(16^{\circ} \mathrm{C}\right)$. Figure 4 presents the thermal protocol for each temperature. Specifically, the FRPspec16, which completed successfully the three thermal loading cycles, was additionally subjected to monotonic, uniaxial tension until failure at the temperature of $50^{\circ} \mathrm{C}$. The information of experiments under elevated temperature is shown in table 2.

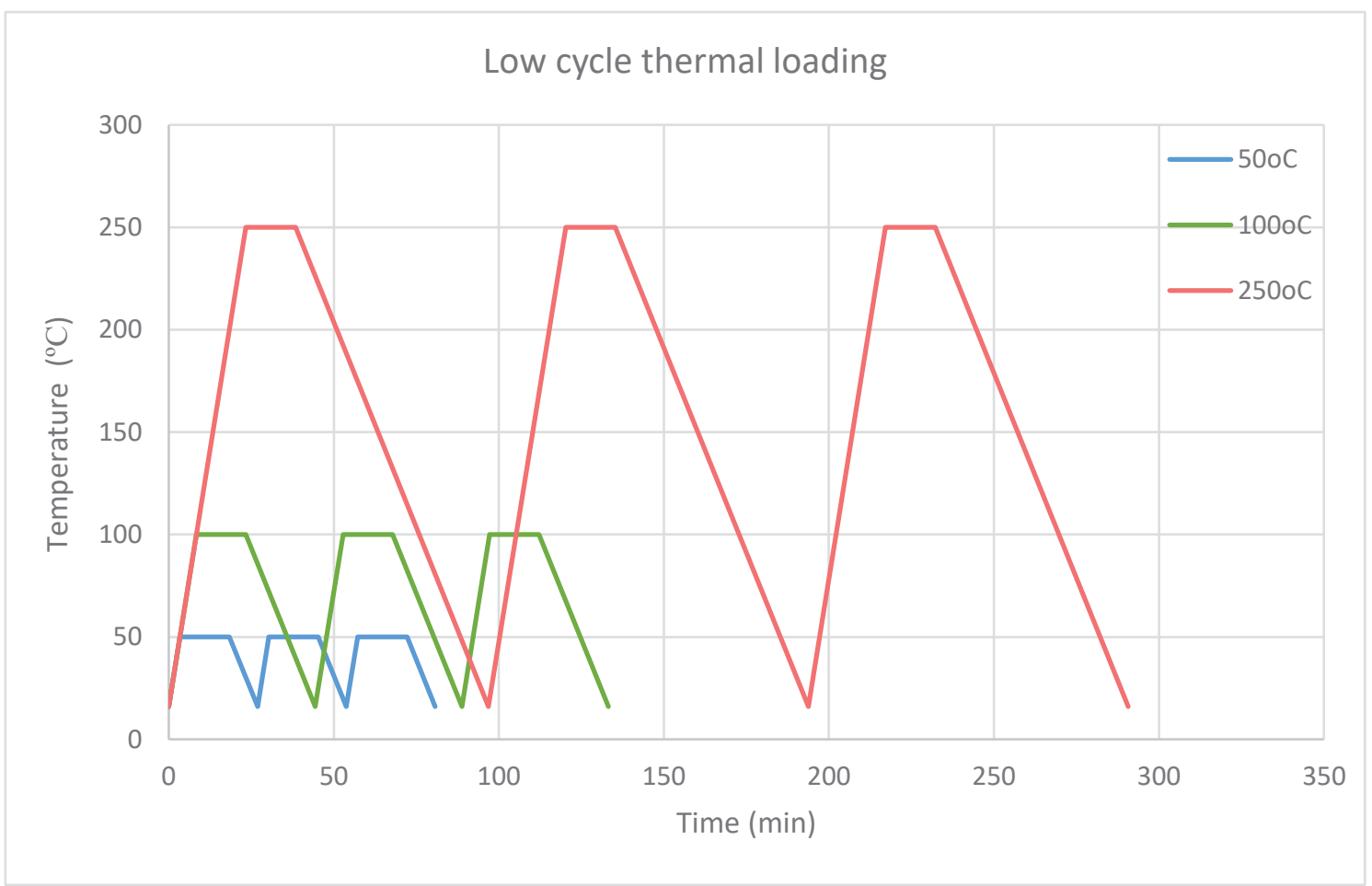

Figure 4: Time - Temperature diagram for cyclic thermal loading (heating to 50,100 and $250^{\circ} \mathrm{C}$ and cooling to $\mathrm{RT}=16^{\circ} \mathrm{C}$ ). 
Table 2: Detailed information of experiments under elevated temperatures.

\begin{tabular}{|c|c|c|c|c|c|}
\hline \multirow[t]{2}{*}{ Name } & \multicolumn{2}{|c|}{$\begin{array}{l}\text { Dimensions } \\
(\mathrm{mm})\end{array}$} & \multirow[t]{2}{*}{ Loading } & \multirow{2}{*}{$\begin{array}{c}\mathbf{T} \\
\left({ }^{\circ} \mathbf{C}\right)\end{array}$} & \multirow[t]{2}{*}{ Comments } \\
\hline & $\mathbf{t}$ & b & & & \\
\hline FRPspec8 & 1.90 & 16.25 & $\mathrm{TL}^{* 3}, \mathrm{MUT}$ & 50 & TL (1 cycle) and MUT up to failure \\
\hline FRPspec11 & 1.99 & 15.96 & TL, MUT & 50 & TL ( 1 cycle) and MUT up to failure \\
\hline FRPspec9 & 1.84 & 16.05 & TL, MUT & 100 & TL ( 1 cycle) and MUT up to failure \\
\hline FRPspec12 & 2.04 & 15.76 & TL, MUT & 100 & TL ( 1 cycle) and MUT up to failure \\
\hline FRPspec10 & 1.89 & 15.96 & TL, MUT & 250 & TL ( 1 cycle) and MUT up to failure \\
\hline FRPspec13 & 1.78 & 13.98 & TL, MUT & 250 & TL ( 1 cycle) and MUT up to failure \\
\hline FRPspec16 & 1.73 & 14.52 & $\begin{array}{l}\text { MUT and } \\
\text { LCTL }^{* 4}\end{array}$ & 50 & $\begin{array}{l}\text { MUT with constant load } 50 \% \text { of the } \\
\text { tensile strength and concurrently } \\
\text { LCTL up to failure ( } \max 3 \text { cycles) }\end{array}$ \\
\hline FRPspec17 & 1.80 & 14.45 & $\begin{array}{l}\text { MUT and } \\
\text { LCTL }\end{array}$ & 100 & $\begin{array}{l}\text { MUT with constant load } 50 \% \text { of the } \\
\text { tensile strength and concurrently } \\
\text { LCTL up to failure ( } \max 3 \text { cycles) }\end{array}$ \\
\hline FRPspec18 & 1.71 & 16.68 & $\begin{array}{l}\text { MUT and } \\
\text { LCTL }\end{array}$ & 100 & $\begin{array}{l}\text { MUT with constant load } 50 \% \text { of the } \\
\text { tensile strength and concurrently } \\
\text { LCTL up to failure ( } \max 3 \text { cycles) }\end{array}$ \\
\hline FRPspec19 & 1.73 & 13.40 & $\begin{array}{l}\text { MUT and } \\
\text { LCTL }\end{array}$ & 250 & $\begin{array}{l}\text { MUT with constant load } 50 \% \text { of the } \\
\text { tensile strength and concurrently } \\
\text { LCTL up to failure (max } 3 \text { cycles) }\end{array}$ \\
\hline FRPspec20 & 1.87 & 11.05 & $\begin{array}{l}\text { MUT and } \\
\text { LCTL }\end{array}$ & 250 & $\begin{array}{l}\text { MUT with constant load } 50 \% \text { of the } \\
\text { tensile strength and concurrently } \\
\text { LCTL up to failure (max } 3 \text { cycles) }\end{array}$ \\
\hline
\end{tabular}

*3Thermal Loading, *4Low Cycle Thermal Loading $(\mathrm{n}=3)$

\section{RESULTS}

Table 4 presents the results of all the CFRP specimens. Concerning to the control specimens, the average tensile strength of dry fibers of the specimens FRPspec1-5, which were monotonically loaded at room temperature up to failure, was $4,410.82 \mathrm{MPa}$, their average ultimate strain was $17.47 \%$ and their average elastic modulus of dry fibers was $252.52 \mathrm{GPa}$. Their stress-strain curves are shown in figure 5.

Table 4: Summarized results

\begin{tabular}{lccccccc}
\hline Name & Loading & $\begin{array}{c}\text { T } \\
\left({ }^{\circ} \mathbf{C}\right)\end{array}$ & $\begin{array}{c}\text { Max } \\
\text { Tensile } \\
\text { Stress } \\
\text { (MPa) }\end{array}$ & $\begin{array}{c}\text { Max } \\
\text { Stress of } \\
\text { dry fi- } \\
\text { bers } \\
(\mathbf{M P a})\end{array}$ & $\begin{array}{c}\text { Max } \\
\text { Strain } \\
\text { (\%o) }\end{array}$ & $\begin{array}{c}\text { Modu- } \\
\text { lus } \\
\text { of dry } \\
\text { fibers } \\
(\mathbf{G P a})\end{array}$ & $\begin{array}{c}\text { Comments / Mode of } \\
\text { failure }\end{array}$ \\
\hline FRPspec1 & MUT & RT(=16) & 719.59 & $4,546.28$ & 17.86 & 254.61 & Fracture of fibers \\
\hline FRPspec2 & MUT & RT & 664.65 & $4,482.52$ & 16.75 & 267.61 & Fracture of fibers \\
\hline FRPspec3 & MUT & RT & 657.99 & $4,361.10$ & 18.53 & 235.35 & Fracture of fibers \\
\hline FRPspec4 & MUT & RT & 711.28 & $4,548.91$ & 18.39 & 247.36 & Fracture of fibers \\
\hline FRPspec5 & MUT & RT & 596.49 & $4,115.30$ & 15.81 & 260.30 & Fracture of fibers \\
\hline FRPspec6 & LCF, & RT & 565.99 & $4,519.17$ & 20.45 & 220.98 & Fracture of fibers \\
& MUT & & & & & & \\
\hline FRPspec14 & LCF, & RT & 646.27 & $4,358.59$ & 21.69 & 200.98 & Fracture of fibers \\
& MUT & & & & & &
\end{tabular}




\begin{tabular}{|c|c|c|c|c|c|c|c|}
\hline FRPspec7 & $\begin{array}{l}\text { LCF, } \\
\text { MUT }\end{array}$ & RT & 531.52 & $4,079.09$ & 16.12 & 253.08 & Fracture of fibers \\
\hline FRPspec15 & $\begin{array}{l}\text { LCF, } \\
\text { MUT }\end{array}$ & RT & 612.95 & $4,395.18$ & 18.84 & 233.25 & Fracture of fibers \\
\hline FRPspec8 & TL, MUT & 50 & 490.90 & $3,615.14$ & 13.67 & 264.52 & Fracture of fibers \\
\hline FRPspec11 & TL, MUT & 50 & 569.99 & $4,396.47$ & 17.68 & 248.67 & Fracture of fibers \\
\hline FRPspec9 & TL, MUT & 100 & 393.61 & $2,807.13$ & 10.14 & 276.95 & Fracture of fibers \\
\hline FRPspec12 & TL, MUT & 100 & 518.15 & $4,097.00$ & 27.66 & 148.11 & Fracture of fibers \\
\hline FRPspec10 & TL, MUT & 250 & 577.98 & $4,234.06$ & 15.51 & 272.99 & Fracture of fibers \\
\hline FRPspec13 & TL, MUT & 250 & 669.88 & $4,621.66$ & 19.60 & 235.80 & Fracture of fibers \\
\hline FRPspec16 & $\begin{array}{l}\text { MUT and } \\
\text { LCTL }\end{array}$ & 50 & 356.98 & $2,393.71$ & 15.21 & 169.27 & $\begin{array}{l}\text { It completed successfully } \\
\text { the three thermal loading } \\
\text { cycles. The values of the } \\
\text { first line refer to the } \\
\text { LCTL under constant ten- } \\
\text { sion and the values of the } \\
\text { second line refer to the } \\
\text { MUT up to failure. }\end{array}$ \\
\hline FRPspec17 & $\begin{array}{l}\text { MUT and } \\
\text { LCTL }\end{array}$ & 100 & 348.07 & $2,428.37$ & 12.95 & 187.46 & $\begin{array}{l}\text { Failure at the heating pro- } \\
\text { cess of the first cycle at } \\
64^{\circ} \mathrm{C} \text {. The values refer to } \\
\text { the LCTL under constant } \\
\text { tension. }\end{array}$ \\
\hline FRPspec18 & $\begin{array}{c}\text { MUT and } \\
\text { LCTL }\end{array}$ & 100 & 317.71 & $2,105.78$ & 24.14 & 87.23 & $\begin{array}{l}\text { Failure at the cooling } \\
\text { process of the first cycle } \\
\text { at } 31^{\circ} \mathrm{C} \text {. The values refer } \\
\text { to the LCTL under con- } \\
\text { stant tension. }\end{array}$ \\
\hline FRPspec19 & $\begin{array}{l}\text { MUT and } \\
\text { LCTL }\end{array}$ & 250 & 388.48 & $2,604.95$ & 15.55 & 167.53 & $\begin{array}{l}\text { Failure at the heating pro- } \\
\text { cess of the first cycle at } \\
61^{\circ} \mathrm{C} \text {. The values refer to } \\
\text { the LCTL under constant } \\
\text { tension. }\end{array}$ \\
\hline FRPspec20 & $\begin{array}{l}\text { MUT and } \\
\text { LCTL }\end{array}$ & 250 & 327.22 & $2,371.75$ & 23.63 & 100.36 & $\begin{array}{l}\text { Failure at the heating pro- } \\
\text { cess of the first cycle at } \\
151^{\circ} \mathrm{C} \text {. The values refer } \\
\text { to the LCTL under con- } \\
\text { stant tension. }\end{array}$ \\
\hline
\end{tabular}




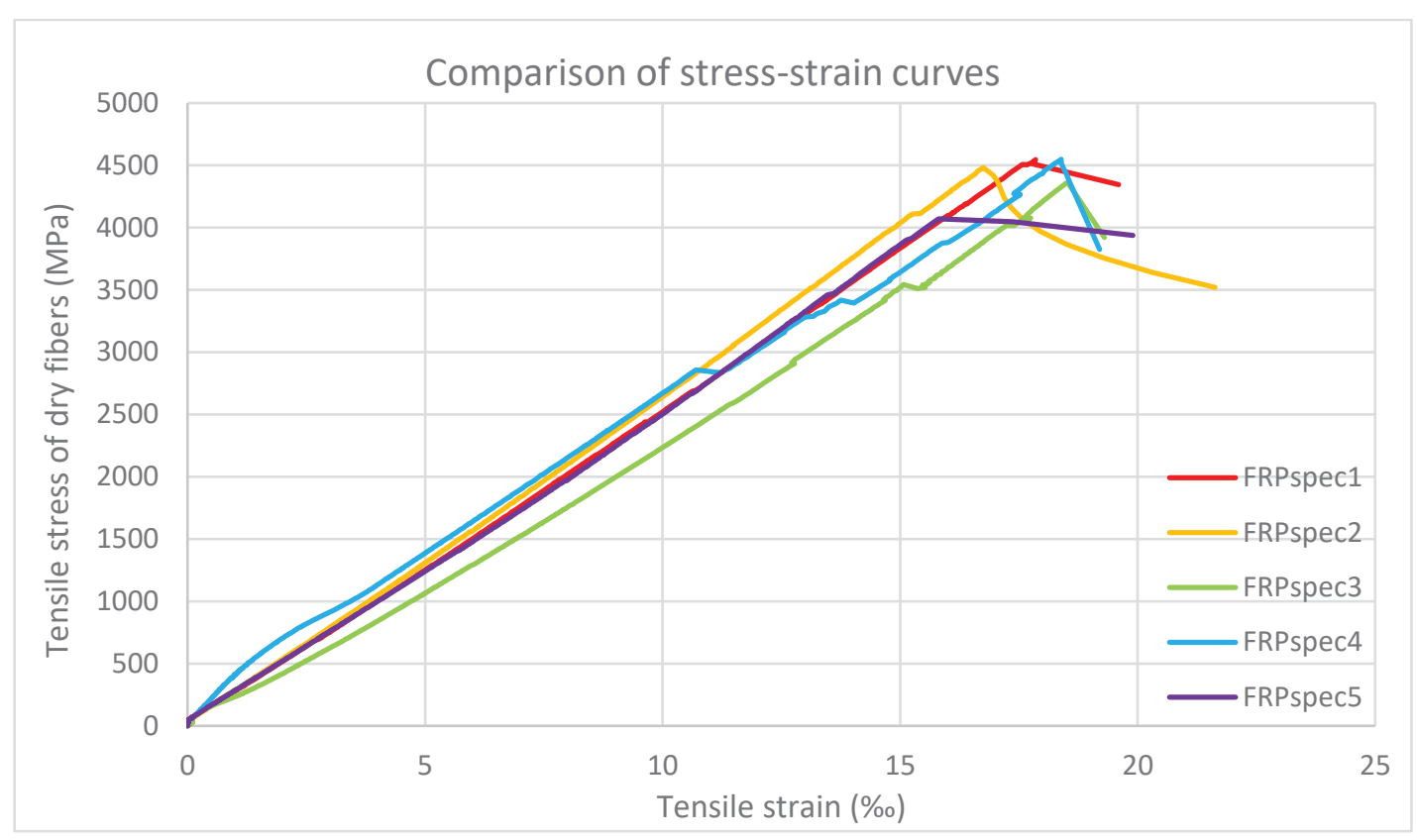

Figure 5: Stress-strain curves for monotonic uniaxial tension at room temperature.

The specimens FRPspec6,14 and FRPspec7,15 were submitted to fatigue tests of fifty loading-unloading cycles with maximum load of $50 \%$ and $75 \%$ of the average tensile strength, respectively. (see figure 6) Resulted from the monotonic, uniaxial tension that followed, the average tensile strength of dry fibers was 4,438.88 MPa and 4,237.14 MPa for the FRPspec6,14 and the FRPspec7,15, respectively. Consequently, the low-cycle fatigue did not affect the specimens FRPspec6,14, but it reduced the CFRPs tensile strength of dry fibers by 3.94\% for FRPspec 7,15. Besides, the average ultimate strain did not appear significant change as its value was $21.07 \%$ and $17.48 \%$ or the FRPspec6,14 and the FRPspec7,15, respectively. It should also be mentioned that low-cycle fatigue does not affect the stiffness of the CFRPs as their elastic modulus of dry fibers remain at the same level. The stress-strain curves of monotonic tensile loading of the specimens are shown in figure 7.

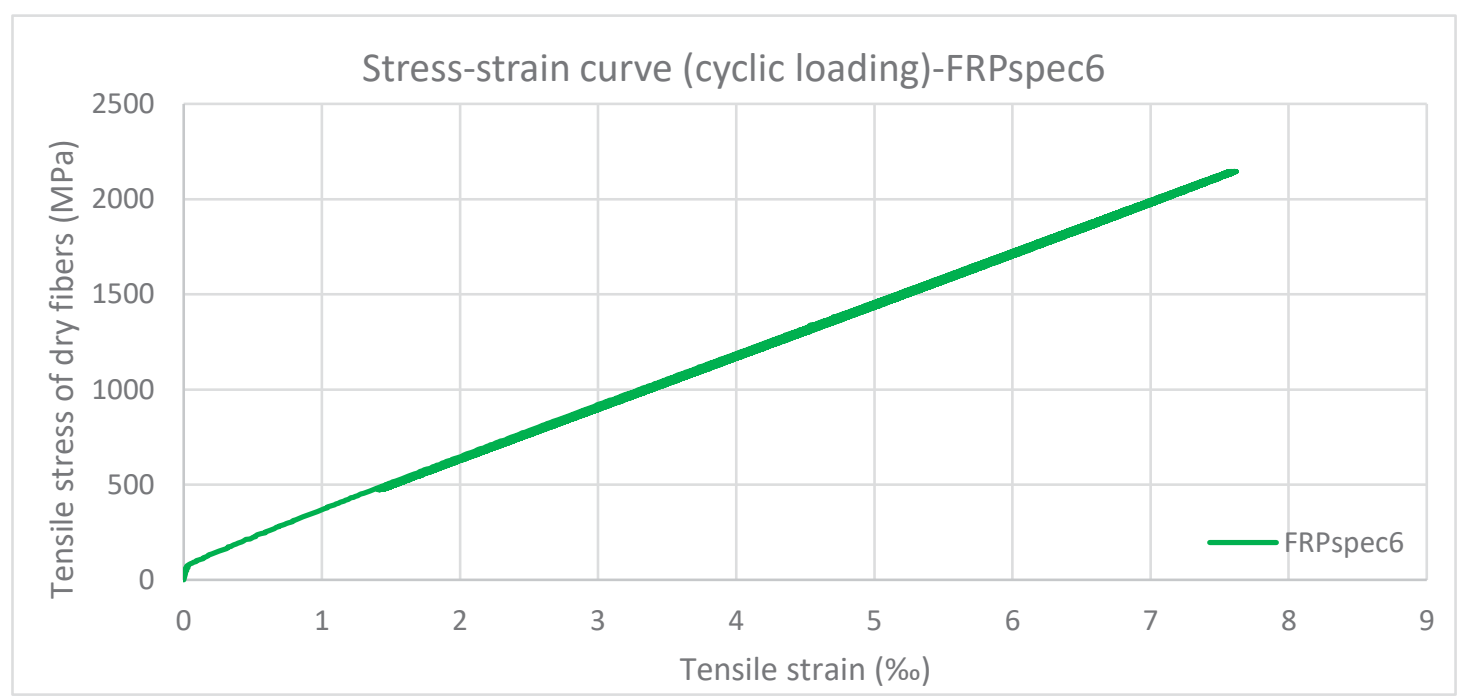




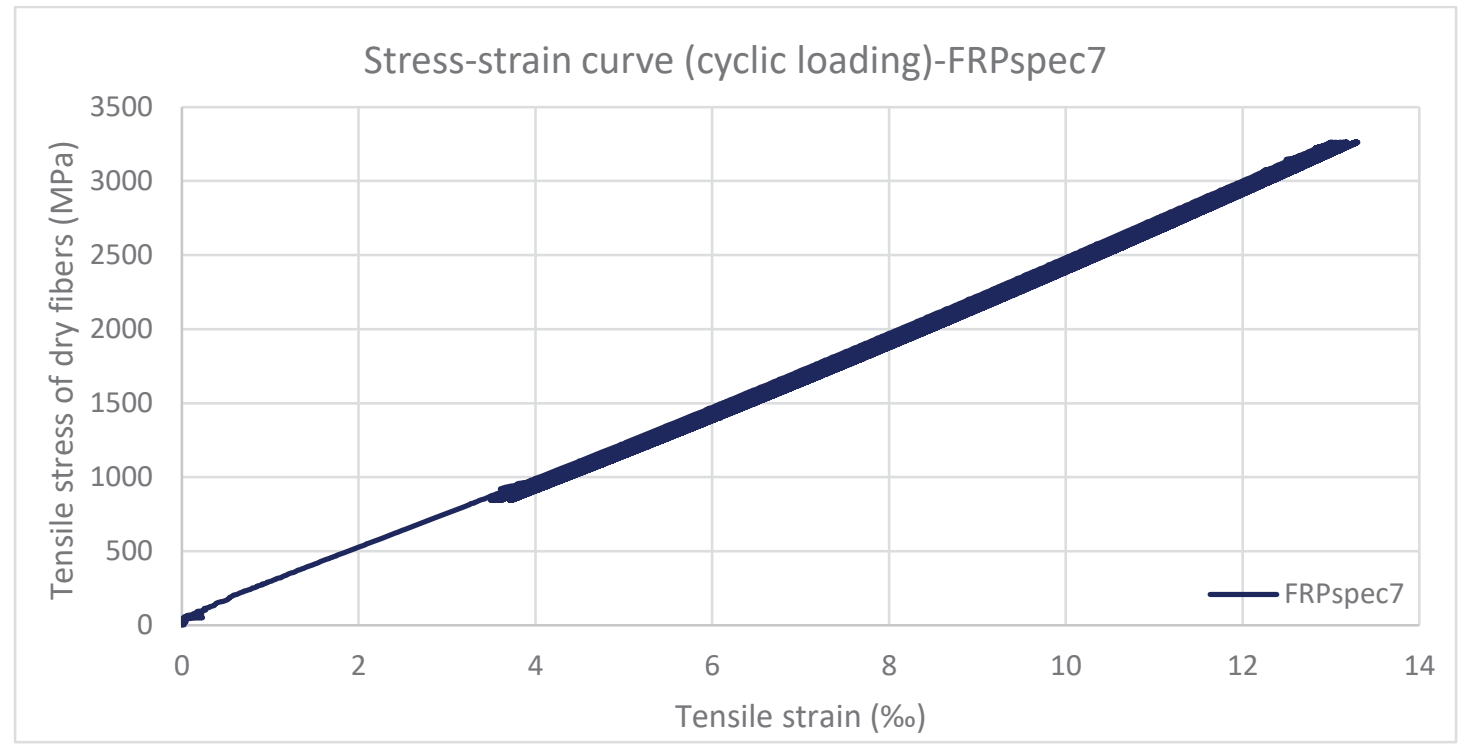

Figure 6: Stress-strain curves for low-cycle fatigue with max load 50\% (FRPspec6) and 75\% (FRPspec7) of the tensile strength.

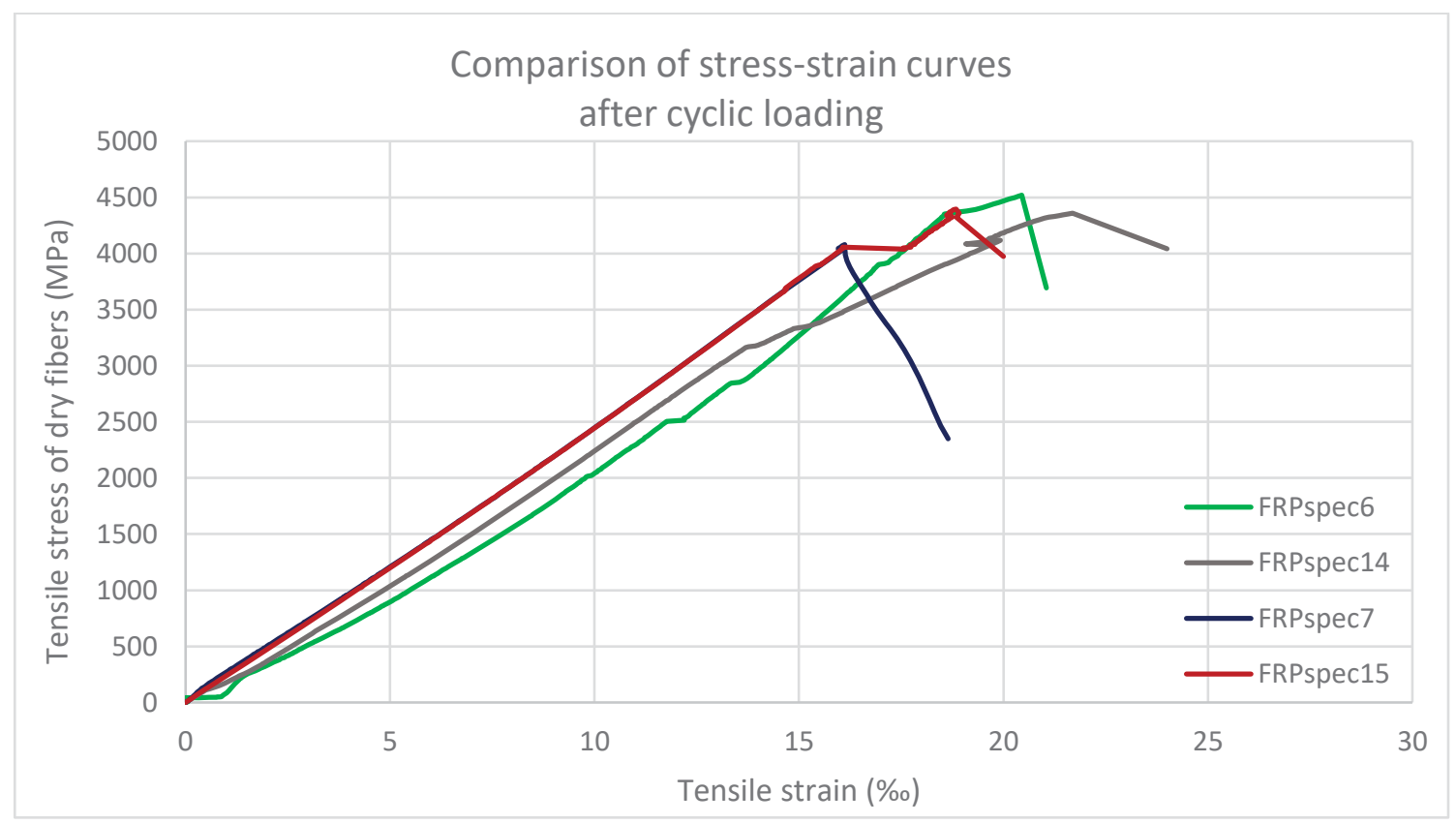

Figure 7: Stress-strain curves of monotonic, uniaxial tension at room temperature after low-cycle fatigue.

The specimens FRPspec8-13,16-20 were exposed to different temperatures during the experiments as it mentioned before. Figure 8 presents the stress-strain curves of monotonic, uniaxial tensile tests which were conducted after the specimens' heating and cooling (FRPspec813). FRPspec8 is an exception as the tensile test was possible to be held at the temperature of $50{ }^{\circ} \mathrm{C}$ without slip of the specimen. The specimen's tensile strength of dry fibers was $3,615.14$ $\mathrm{MPa}$ and its ultimate strain was $13.67 \%$. Observing the samples after heating, those exposed to 100 and $250{ }^{\circ} \mathrm{C}$ softened a lot and the resin turned easily into powder with the application of pressure by the machine. In addition, the FRPspec10,13 acquired a dark black colour. However, it was observed that the samples regained their hardness after cooling and the resin was no longer frail. A worth noting conclusion is that the tensile strength of dry fibers of the specimens after exposure at the temperatures of 50,100 and $250{ }^{\circ} \mathrm{C}$ for 30 min did not appear decrease. 
The fact that the samples were left to cool significantly contributed to this result. The ultimate strain and the elastic modulus of dry fibers of these specimens did not appear any important change, too.

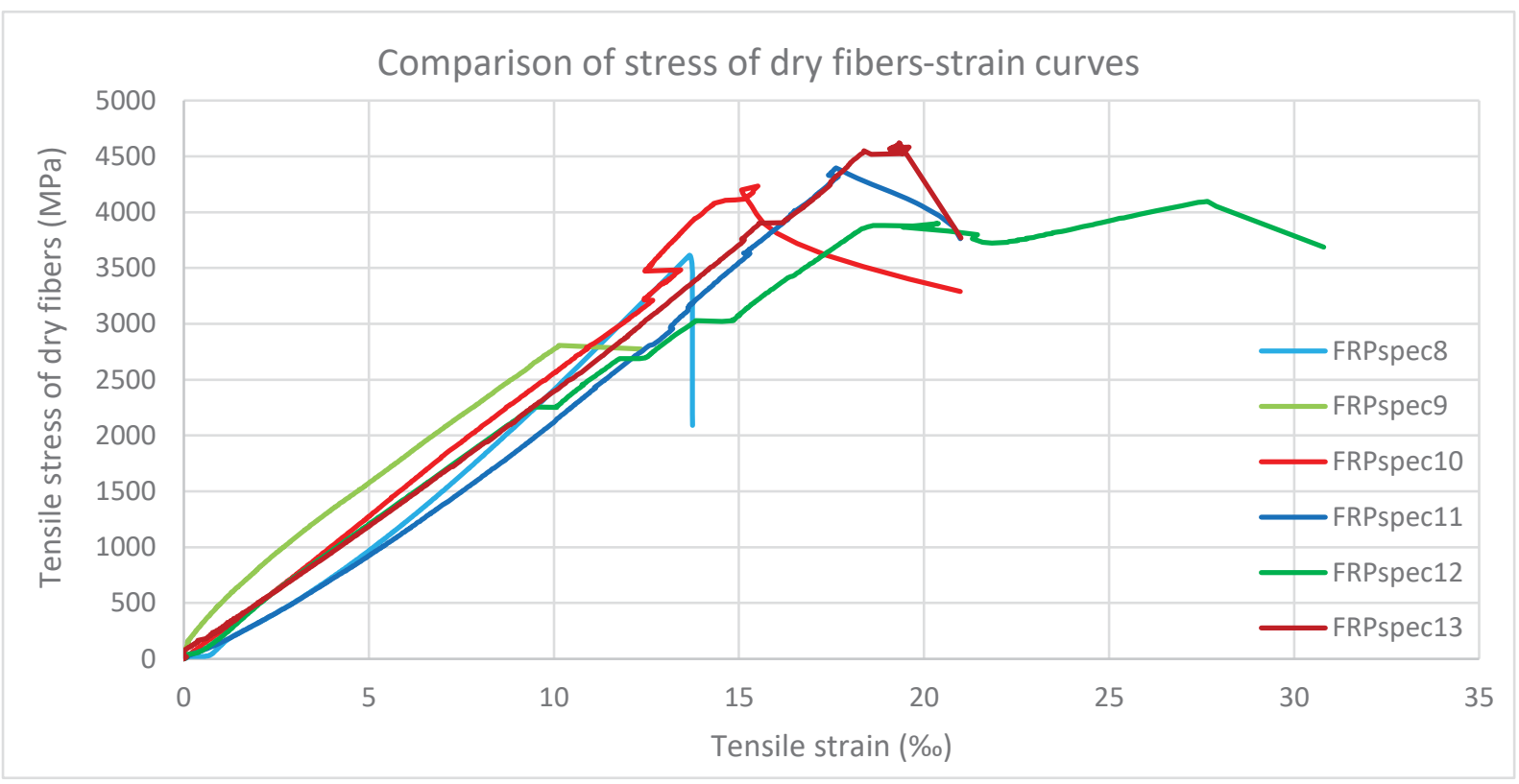

Figure 8: Stress-strain curves of monotonic, uniaxial tensile tests after exposure to the temperatures of $50{ }^{\circ} \mathrm{C}$ (FRPspec 8,11$), 100{ }^{\circ} \mathrm{C}$ (FRPspec9b,12) and $250{ }^{\circ} \mathrm{C}$ (FRPspec10,13) and then cooling.

The specimens FRPspec16-20 were under both constant tensile load and thermal loading of maximum three heating-cooling cycles. The stress-strain curves of these tests are shown in figure 9. The only sample which managed to complete three heating-cooling cycles without failure was FRPspec16. The maximum temperature of each cycle at this test was $50{ }^{\circ} \mathrm{C}$. After the thermal cyclic loading, FRPspec16 was tested under monotonic tension. The specimen's tensile strength of dry fibers was 3,269.66 MPa, its ultimate strain was $19.32 \%$ and its elastic modulus of dry fibers was $169.27 \mathrm{GPa}$. According to this, the tensile strength and the elastic modulus of dry fibers are decreased after the heating-cooling cycles.

At higher temperatures, heating combined with the continuous loading had an important impact on the CFRPs' strength as the four samples failed during the first cycle. FRPspec17 failed at the heating process at $64{ }^{\circ} \mathrm{C}$, FRPspec 18 failed at the cooling process at $31{ }^{\circ} \mathrm{C}$, FRPspec 19 failed at the heating process at $61{ }^{\circ} \mathrm{C}$ and FRPspec 20 failed at the heating process at $151{ }^{\circ} \mathrm{C}$. The first two of these samples were supposed to be exposed to maximum temperature of $100^{\circ} \mathrm{C}$ and the last two to maximum temperature of $250{ }^{\circ} \mathrm{C}$.

It is necessary to mention that the heating rate was $10^{\circ} \mathrm{C} / \mathrm{min}$. Because of this slow rate, the specimens remained at high temperature for a long time. If the heating rate was faster, may the FRPs resisted for more thermal loading cycles. The deterioration of the CFRP, due to the long time remaining at high temperature, was also obvious from the mode of failure of the FRPspec20 and its fibers' dark colour. Some of the specimens which were exposed to elevated temperatures are shown after their failure in figure 10.

From the specimens which were supposed to be exposed to maximum temperature of $100{ }^{\circ} \mathrm{C}$ and $250{ }^{\circ} \mathrm{C}$, the FRPspec 18 and FRPspec 20 remained at high temperatures for a longer time than the FRPspec17 and the FRPspec19, which failed earlier. It is also evident from the figure 9 that staying at high temperatures under constant load for longer time causes greater deflections and significant reduction in the modulus of elasticity. The ultimate strain and the elastic 
modulus of dry fibers of the FRPspec 18 were $24.14 \%$ and $87.23 \mathrm{GPa}$, respectively, and of the FRPspec 20 were $23.63 \%$ o and $100.36 \mathrm{GPa}$, respectively.

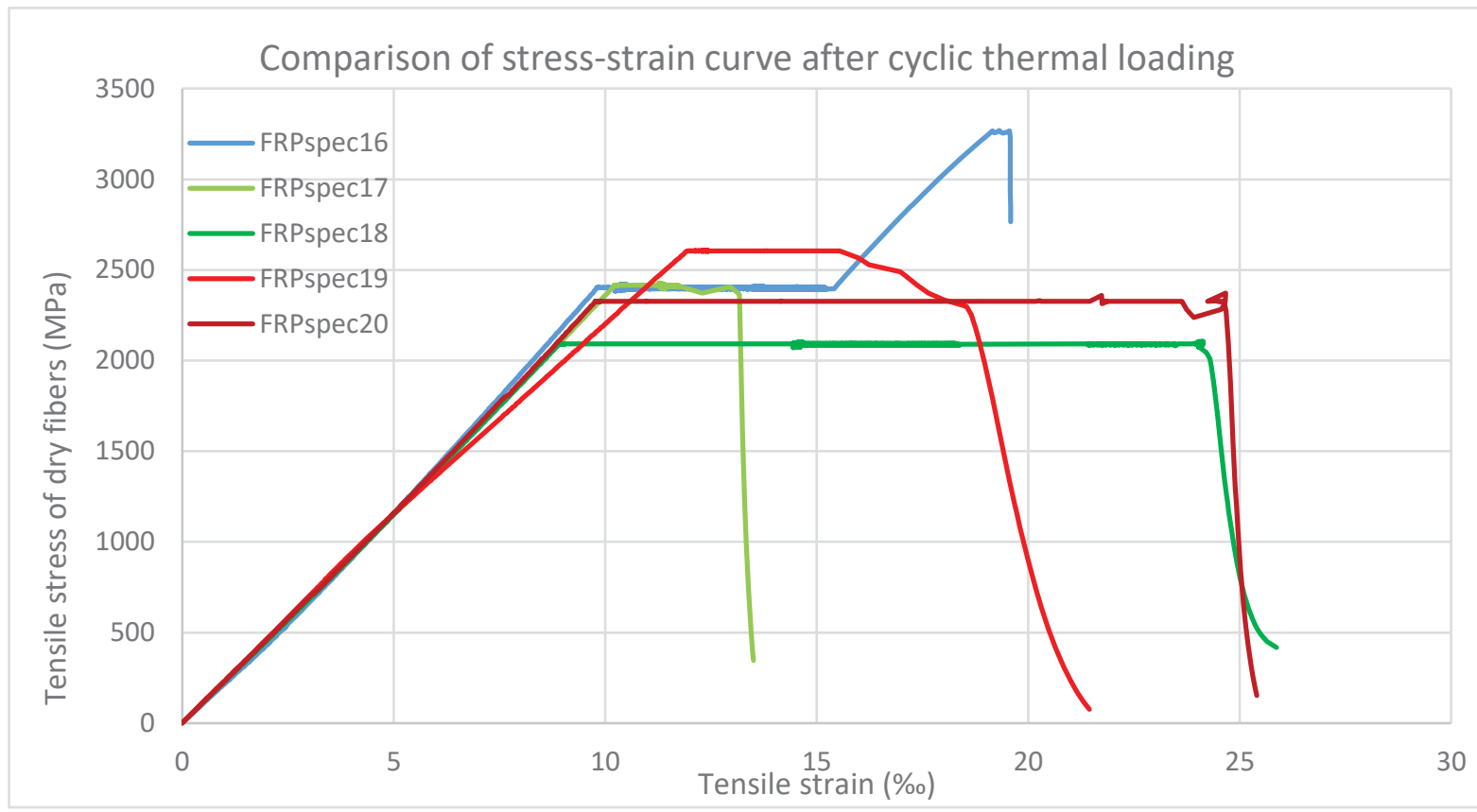

Figure 9: Stress-strain curves of low-cycle thermal loading under constant tensile load. The maximum temperatures of heating-cooling cycles were $50{ }^{\circ} \mathrm{C}$ (FRPspec16), $100{ }^{\circ} \mathrm{C}(\mathrm{FRPspec} 17,18)$ and $250{ }^{\circ} \mathrm{C}(\mathrm{FRPspec} 19,20)$.
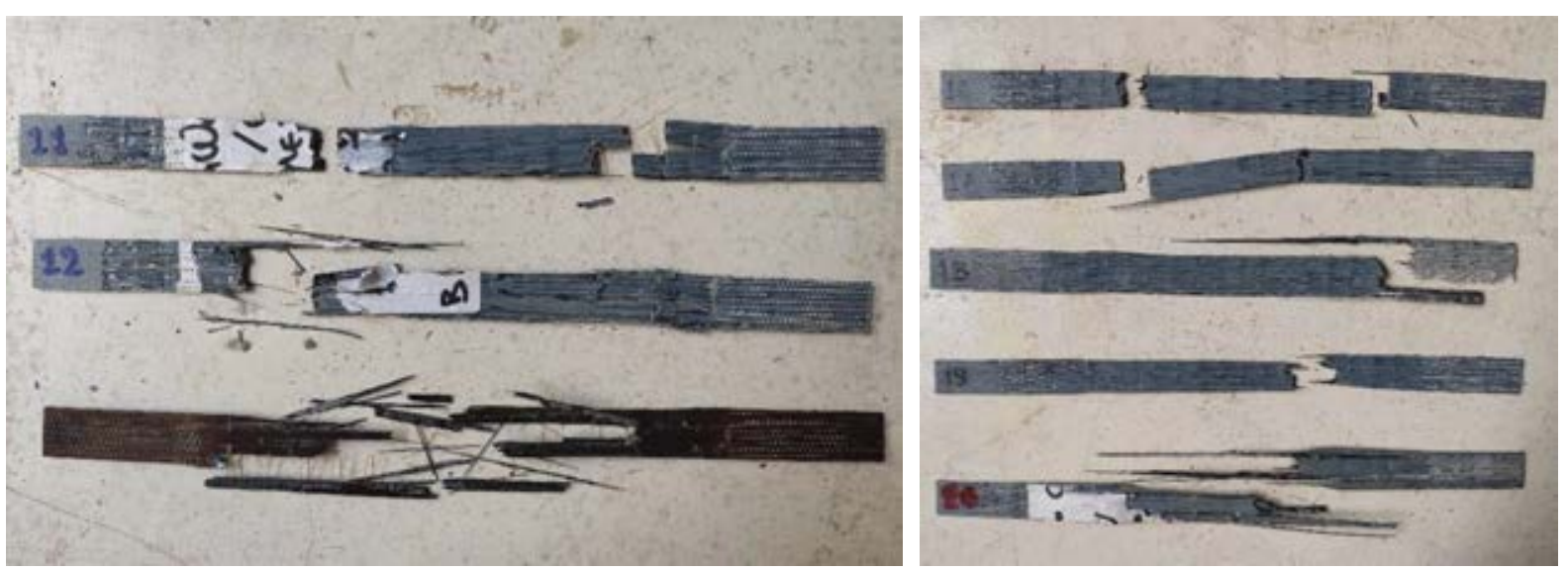

Figure 10: Specimens, exposed to elevated temperatures, after their failure.

FRPspec 11,12,13 were exposed to 50,100 and $250{ }^{\circ} \mathrm{C}$, respectively (TL, MUT).

FRPspec16, FRPspec17,18 and FRPspec19,20 were exposed to 50,100 and $250{ }^{\circ} \mathrm{C}$, respectively

(MUT and LCTL).

\section{CONCLUSION}

- At room temperature CFRP laminates appear high tensile strength and elastic modulus.

- Low-cycle fatigue at room temperature reduces in a small percentage the CFRP laminates' tensile strength. This reduction is obvious when the maximum load of the cycle is high enough.

- Low-cycle fatigue at room temperature does not affect the stiffness of the CFRPs, as their elastic modulus remain at the same level. 
- When CFRP laminates are exposed to elevated temperatures $\left(100{ }^{\circ} \mathrm{C}, 250{ }^{\circ} \mathrm{C}\right)$ the resin softens and turns easily into powder if pressure is applied. In addition, the FRPs acquire a dark black colour at $250{ }^{\circ} \mathrm{C}$.

- Because of the resin's deterioration under elevated temperatures, the CFRP specimens slip from the machine's grips during the tensile testing. Therefore, better gripping is needed.

- CFRPs cooled after exposure to elevated temperatures, regain their hardness and the resin is no longer frail. Their tensile strength does not show decrease.

- The cyclic thermal loading under constant tensile load causes degradation of CFRP laminates, as their tensile strength is reduced after the heating-cooling cycles.

- The cyclic thermal loading under constant tensile load reduces the elastic modulus of CFRP laminates. The higher temperatures the CFRPs are exposed to, the greater reduction of the elastic modulus is caused.

- The longer time the CFRP laminates remain at high temperatures under constant tensile load, the greater deflections and reduction in their elastic modulus are caused.

\section{ACKNOWLEDGEMENTS}

Part of the research "MECHANICAL PROPERTIES CHARACTERISATION OF FRPS UNDER ELEVATED TEMPERATURES" has been co-funded by Greece and European Union through the Operational Program "EDBM-103: SUPPORT FOR RESEARCHERS EMPHASIZING YOUNG RESEARCHERS - $2^{\text {nd }}$ CYCLE" (project code: 5047899) which are gratefully acknowledged.
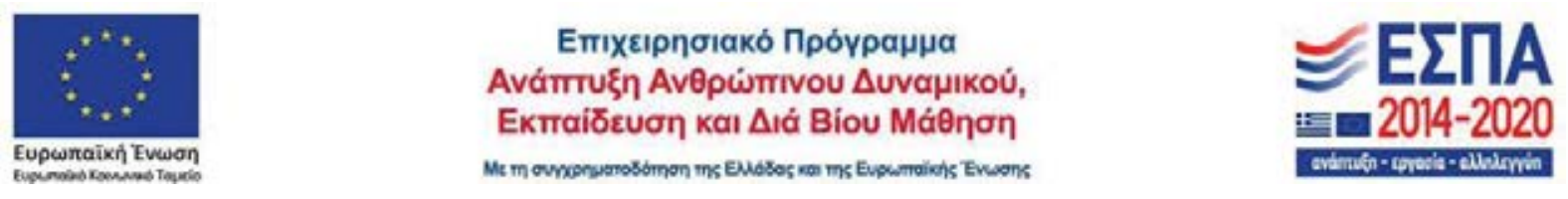

\section{REFERENCES}

[1] M.Z. Naser, R.A. Hawileh, J.A. Abdalia, Fiber-reinforced polymer composites in strengthening reinforced concrete structures: A critical review. Engineering Structures, 198, 2019.

[2] S.B. Singh, A. Sethi, A Review of Performance of Fibre Reinforced Polymer Strengthened Structures Under Fire Exposure. Civil Engineering Department, Birla Institute of Technology and Science, Pilani, India, 2017.

[3] H. Ashrafi, M. Bazli, E.P. Najifabadi, A.V. Oskouei, The effect of mechanical and thermal properties of FRP bars on their tensile performance under elevated temperatures, Construction and Building Materials, 157, 1001-1010, Tehran, Iran, 2017

[4] K. Spirakos, Reinforcement of structures for seismic loads, 288, 176-177, Athens, 2004

[5] S. Piliafa, Investigation of the thermomechanical for smart materials to monotonic and low-cycle fatigue conditions, 71, Aristotle University of Thessaloniki, Greece, 2020 